\title{
Sodium content and labelling of processed and ultra-processed food products marketed in Brazil
}

\author{
Carla Adriano Martins ${ }^{1,2}$, Anete Araújo de Sousa ${ }^{1,2,3}$, Marcela Boro Veiros ${ }^{1,2,3}$ \\ David Alejandro González-Chica ${ }^{1,3}$ and Rossana Pacheco da Costa Proença ${ }^{1,2,3, *}$ \\ 'Nutrition Post-Graduate Program, Federal University of Santa Catarina, Campus Universitário, Trindade, \\ 88040-900 Florianópolis, SC, Brazil: ${ }^{2}$ Nutrition in Foodservice Research Centre (NUPPRE), Federal University \\ of Santa Catarina, Florianópolis, SC, Brazil: ${ }^{3}$ Nutrition Department, Federal University of Santa Catarina, \\ Florianópolis, SC, Brazil
}

Submitted 3 August 2013: Final revision received 5 July 2014: Accepted 15 July 2014: First published online 28 August 2014

\begin{abstract}
Objective: To analyse the $\mathrm{Na}$ content and labelling of processed and ultraprocessed food products marketed in Brazil.

Design: Cross-sectional study.

Setting: A large supermarket in Florianopolis, southern Brazil.

Subjects: Ingredient lists and $\mathrm{Na}$ information on nutrition labels of all processed and ultra-processed pre-prepared meals and prepared ingredients, used in lunch or dinner, available for sale in the supermarket.

Results: The study analysed 1416 products, distributed into seven groups and forty-one subgroups. Five products did not have $\mathrm{Na}$ information. Most products (58.8\%; $95 \%$ CI 55.4, 62.2\%) had high Na content (>600 mg/100 g). In $78.0 \%$ of the subgroups, variation in $\mathrm{Na}$ content was at least twofold between similar products with high and low Na levels, reaching 634-fold difference in the 'garnishes and others' subgroup. More than half of the products $(52.0 \%$; $95 \% \mathrm{CI}$ $48 \cdot 2,55.6 \%)$ had at least one Na-containing food additive. There was no relationship between the appearance of salt on the ingredients list (first to third position on the list) and a product's Na content (high, medium or low; $P=0.08$ ). Conclusions: Most food products had high $\mathrm{Na}$ content, with great variation between similar products, which presents new evidence for reformulation opportunities. There were inconsistencies in $\mathrm{Na}$ labelling, such as lack of nutritional information and incomplete ingredient descriptions. The position of salt on the ingredients list did not facilitate the identification of high-Na foods. We therefore recommend a reduction in $\mathrm{Na}$ in these products and a review of Brazilian legislation.
\end{abstract}

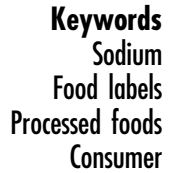

Processed food products are a major source of $\mathrm{Na}$ in common diets and the increased consumption of these products has become a public health problem due to their high $\mathrm{Na}$ content ${ }^{(1-8)}$, which is related to increased risk of developing chronic non-communicable diseases ${ }^{(6)}$.

Among processed foods, pre-prepared meals and prepared ingredients (classified by Monteiro et al. ${ }^{(9)}$ as processed and ultra-processed food products) are higher in $\mathrm{Na}$ compared with fresh foods ${ }^{(10)}$. In the USA, mixed dishes constitute $23 \%$ of the population's total $\mathrm{Na}_{\text {intake }}{ }^{(11)}$. In Brazil, an increase in processed food purchases was observed between 1974 and 2008, amounting to $37 \%$ for prepared foods and processed mixtures, $80 \%$ for pre-prepared meals and $300 \%$ for sausages ${ }^{(12,13)}$.

For Brazilians, these types of food product are increasingly being incorporated into everyday meals, including lunch and dinner, replacing and/or complementing their basic diet, which is characterized by rice, beans, meat and salad $^{(14-16)}$. The average Brazilian consumes $3200 \mathrm{mg} \mathrm{Na} / \mathrm{d}$, which is higher than the maximum intake recommended by the WHO and the FAO ${ }^{(5,17)}$.

Faced with increasing salt and $\mathrm{Na}$ consumption among their populations ${ }^{(3)}$, countries around the world are taking measures to reduce the intake of this nutrient. In this context, food labelling has been used as an important strategy to inform consumers and restrict $\mathrm{Na}$ intake ${ }^{(18)}$.

Labelling is recommended in the WHO Global Strategy on Diet, Physical Activity and Health ${ }^{(19)}$ as a tool to support food choices at the time of purchase, and in order to fulfil its role the presentation of mandatory information on labels must be clear, legible, standardized and easily comprehensible for consumers ${ }^{(20)}$. 
In Brazil, nutrition labelling on packaged foods and drinks (including information about $\mathrm{Na}$ ) has been mandatory since $2001^{(21)}$. This information must be described in milligrams per serving, with the percentage daily value (\%DV) calculated according to an average of $2400 \mathrm{mg} \mathrm{Na} / \mathrm{d}$. Values less than $5 \mathrm{mg} \mathrm{Na} / 100 \mathrm{~g}$ food are considered insignificant amounts, i.e. 'zero sodium'(22,23). It is also mandatory to present a list of ingredients in descending order according to the proportions used, and food additives must be described directly after the foods ${ }^{(24)}$. Thus, the Brazilian Dietary Guidelines recommend checking the position of salt in the ingredients list on processed foods to inform about salt content ${ }^{(25)}$, since the product could potentially have a high concentration of this substance when it appears as one of the first ingredients ${ }^{(25-27)}$.

Although labelling is an important tool for reducing the population's $\mathrm{Na}$ intake ${ }^{(18,28)}$, it has hardly been explored scientifically in Brazil. The high $\mathrm{Na}$ content and high variability among similar products sold in supermarkets has long been recognized ${ }^{(8,29,30)}$. Knowing these contents (and their variations) is important for defining public policy, as exemplified by successful initiatives for reformulation aimed at reducing the $\mathrm{Na}$ content in food products marketed in several countries ${ }^{(18,28,31,32)}$. However, there is currently no good scientific evidence on the Na content (and its variation) in processed foods marketed in Brazil. Given that pre-prepared meals and prepared ingredients contribute to increased $\mathrm{Na}$ intake by the population ${ }^{(11,28-30)}$ and that an increase in the purchase of these products by the Brazilian population has been observed ${ }^{(10,12,16)}$, the present study analysed the labelling and $\mathrm{Na}$ content of processed and ultra-processed pre-prepared meals and prepared ingredients marketed in Brazil and used in main meals, specifically lunch or dinner.

\section{Methods}

\section{Data collection}

The present study was cross-sectional in design and evaluated $\mathrm{Na}$ labelling of processed food products sold in a supermarket in the city of Florianopolis, southern Brazil. The supermarket was chosen intentionally and belongs to one of the ten largest supermarket chains in Brazil ${ }^{(33)}$, with twenty-six stores in the southern region of Brazil, six of which are located in Florianopolis. The products sold in this store are similar to those sold in other large supermarket chains throughout the country. The data were collected from October to December 2011. The supermarket manager authorized the research.

Collection of label information was carried out with a pre-tested instrument for the following analysis variables: (i) product identification; (ii) ingredients list (appearance and position of salt on the list, compound ingredients and Na-containing food additives appearing on the list); and (iii) $\mathrm{Na}$ information ( $\mathrm{Na}$ in the nutritional information, serving size in grams and $\mathrm{Na}$ content in milligrams per serving). For the purpose of the study a compound ingredient was defined as any ingredient included on the list that is composed of two or more ingredients ${ }^{(24)}$. Food additives containing $\mathrm{Na}$ were identified using the specific Brazilian resolution for food additives ${ }^{(34)}$ and Mercosul's Harmonized General List of Food Additives and Their Functional Classes $^{(35)}$.

The data collection team received training and participated in the instrument's pilot test. For quality control, information on two key questions (Na content in milligrams per serving and position of first appearance of salt on the ingredients list) was collected twice for $3 \cdot 2 \%$ of the foods analysed ( $n$ 44). According to the Bland-Altman test, the difference in means for the variable ' $\mathrm{Na}$ content in milligrams per serving' was $0.05 \mathrm{mg}$ (interval of $\pm 2 \mathrm{SD}$ of -0.5 and 0.6 ), while the $\kappa$ value for the variable 'position of the first appearance of salt on the ingredients list' was 1.00.

\section{Inclusion criteria for food products in the study}

The study included all those food products covered under Brazilian nutrition labelling legislation ${ }^{(23)}$ which have the following characteristics: (i) appearance of $\mathrm{Na}$ on the ingredients list; (ii) classified as processed or ultra-processed food products; (iii) pre-prepared meal or prepared ingredients; and (iv) habitually used by the Brazilian population in lunch and dinner meals ${ }^{(5,14,15,36-38)}$.

To assess the true variability in $\mathrm{Na}$ content for each type of specific product, products that did not include $\mathrm{Na}$ among their ingredients were only included in the sample when other products with similar characteristics contained this ingredient. Information on the packaging of identical products of different sizes was recorded separately because their ingredients lists also differed. Products habitually used by the Brazilian population in lunch and dinner meals were defined based on Brazilian literature ${ }^{(5,14,15,36-38)}$. Bread was not included in the analyses, as Brazilians do not customarily eat these products in the meals studied. We also excluded products that were fractionated, labelled and marketed by the supermarket itself, since such products are not required to be labelled in $\mathrm{Brazil}^{(23)}$.

\section{Statistical treatment and analysis of data}

The collected data were entered into two separate databases and later checked for errors and validated in EpiData $^{\circledR}$ 3.1 (EpiData Association, Odense, Denmark). The products were distributed into seven groups and forty-one subgroups predefined by Brazilian nutrition labelling legislation to describe serving sizes for packaged foods ${ }^{(22)}$. Since no product analysed in the present study was part of Group VII of this legislation (Group VII: Sugar and products that provide energy from carbohydrates and fats), this group is not reported in the analyses. A quantity equivalence of $\mathrm{Na}$ in milligrams per $100 \mathrm{~g}$ or $100 \mathrm{ml}$ of food was determined for all the products based on serving size information. Na content in milligrams per $100 \mathrm{~g}$ 
or $100 \mathrm{ml}$ of food was classified as high content (>600 mg $\mathrm{Na})$, medium content ( $>120$ and $\leq 600 \mathrm{mg} \mathrm{Na})$ and low content ( $\leq 120 \mathrm{mg} \mathrm{Na}$ ), according to the Traffic Light Labels of the UK Food Standards Agency ${ }^{(39)}$. The first appearance of salt on the ingredients list was treated as a dichotomous variable (first to third position; fourth position or more).

We conducted a descriptive statistical analysis, presenting absolute and relative frequency, median $\mathrm{Na}$ content, percentiles and relationships between subgroup percentiles. Data dispersion was presented in the 2nd and 98th percentiles (P2-P98) due to the asymmetry of the variable ' $\mathrm{Na}$ content in milligrams per $100 \mathrm{~g}$ or $100 \mathrm{ml}$ of food' and to have an overview of information variability without having the products with extreme values ( $n$ 55) influence the results. This interval therefore represents the dispersion of $96 \%$ of the food products. The ratio between the 98th and 2nd percentiles was assessed based on these values, with the aim of establishing the differences in $\mathrm{Na}$ content between similar products. In order to facilitate calculation of the $\mathrm{P} 98 / \mathrm{P} 2$ ratio for products containing $0 \mathrm{mg} \mathrm{Na} / 100 \mathrm{~g}$, the value of $5 \mathrm{mg} \mathrm{Na} / 100 \mathrm{~g}$ was used, which is an amount defined as insignificant by Brazilian nutrition labelling legislation ${ }^{(23)}$.

A $\chi^{2}$ test was used to assess the association between product $\mathrm{Na}$ content and the first appearance of salt on the ingredients list. Due to infeasibility for inclusion in this analysis, the following products were excluded from this analysis: (i) those that included salt as their main ingredient (complete seasonings and those prepared for broth, $n$ 103), since none of these products would be consumed directly, affecting interpretation of the data; (ii) those that did not include salt on the ingredients list ( $n$ 100); and (iii) those that did not have $\mathrm{Na}$ information on the nutrition label ( $n$ 5).

The statistical software package Stata ${ }^{\circledR}$ version 11.0 was used for the statistical analyses, with $P<0.05$ considered indicative of statistical significance.

\section{Results}

Of the $4538 \mathrm{Na}$-containing processed food products available for sale at the supermarket, 1416 were classed as processed and ultra-processed pre-prepared meals and prepared ingredients used for lunch and dinner. Therefore, the present study analysed 1416 products by 211 different manufacturers $-87.6 \%$ of the products having been produced in Brazil. The other products were from Argentina ( $n$ 35), Italy ( $n$ 27), Spain ( $n$ 24), Germany ( $n$ 22), the USA ( $n$ 21), Peru ( $n$ 10), Uruguay ( $n 7)$, Belgium ( $n$ 5), Chile ( $n$ 5), France ( $n$ 5), China ( $n$ 4), Mexico $(n 4)$, Poland ( $n$ 3), Portugal ( $n$ 2) and Ecuador ( $n$ 1).

\section{Nutritional information}

Of the products analysed, five (0.4\%) did not include $\mathrm{Na}$ information on the nutrition label. The remaining 1411 products were distributed into seven groups and forty-one subgroups.

Classification of $\mathrm{Na}$ content $(\mathrm{mg} / 100 \mathrm{~g}$ or $100 \mathrm{ml})$ according to the UK Food Standards Agency

Of all the products with Na nutrition information ( $n$ 1411), $58.8 \%$ (95\% CI 55.4, 62.2\%) were classified as having a high $\mathrm{Na}$ content $(>600 \mathrm{mg} / 100 \mathrm{~g}$ or $100 \mathrm{ml}$ ) and $7.0 \%$ (95\% CI 2.9, 14.2\%) were classified as having low $\mathrm{Na}$ content $(\leq 120 \mathrm{mg} / 100 \mathrm{~g} \text { or } 100 \mathrm{ml})^{(39)}$. In the $\mathrm{Na}$ content classification by food group, the majority of products included in groups VI (98.4\%), V (70.0 \%), I (64.7\%), VIII $(61.7 \%)$ and IV (52.0\%) had high Na content per $100 \mathrm{~g}$ or $100 \mathrm{ml}$ (Fig. 1).

Na content $\mathrm{v}$. first appearance of salt on ingredients list Figure 2 presents the analysis of $\mathrm{Na}$ content in the nutritional information (classified according to the UK Food Standards Agency ${ }^{(39)}$ ) and the position in which salt appears in the studied products' ingredients lists.

Regarding the position in which salt first appears on the ingredients list, of the 1208 products analysed, 37.1\% (95\% CI 32.6, 41.7\%) listed salt between the first and third positions. There was no difference in this percentage when compared among products of low, medium or high Na content $(P=0 \cdot 08)$. Other cut-off points for the position of salt were used, but the percentages among the three $\mathrm{Na}$ content categories remained similar in all cases.

\section{Na content by food product group and subgroup}

Based on $\mathrm{Na}$ information, we defined median $\mathrm{Na}$ content by food group and subgroup, the P2-P98 for each subgroup, as well as the relationship between these percentiles (Table 1).

A large variation in $\mathrm{Na}$ content within different subgroups was found. In almost half of the subgroups (44\%) the highest-Na product had an $\mathrm{Na}$ concentration at least ten times higher than the product with the lowest $\mathrm{Na}$, and in about $17 \%$ of the subgroups analysed the differences were even more extreme (about fifty times higher or more). This wide variation occurred in subgroups classified as high, medium and low in Na.

\section{Ingredients list}

\section{Food products with added $\mathrm{Na}$}

On the ingredients lists, fourteen different nomenclatures for salt were found: salt, sodium chloride, refined salt, refined iodized salt, iodized salt, marine salt, sea salt, reducedsodium salt, hyposodic salt, coarse salt, special coarse salt, iodized coarse salt, cured salt and low salt. Of the 1543 citations found, salt was the most common (86.3\%; $95 \%$ CI $84 \cdot 3,88 \cdot 1 \%)$. In 347 citations, salt composed part of twentyseven different types of compound ingredients, including sauces, condiments/seasonings, pasta, cheeses, cheesebased preparations, meats, meat-based products, filling, bread, flour, pepper-based preparations, flavour enhancers, antioxidants, brine and artificial colouring. 


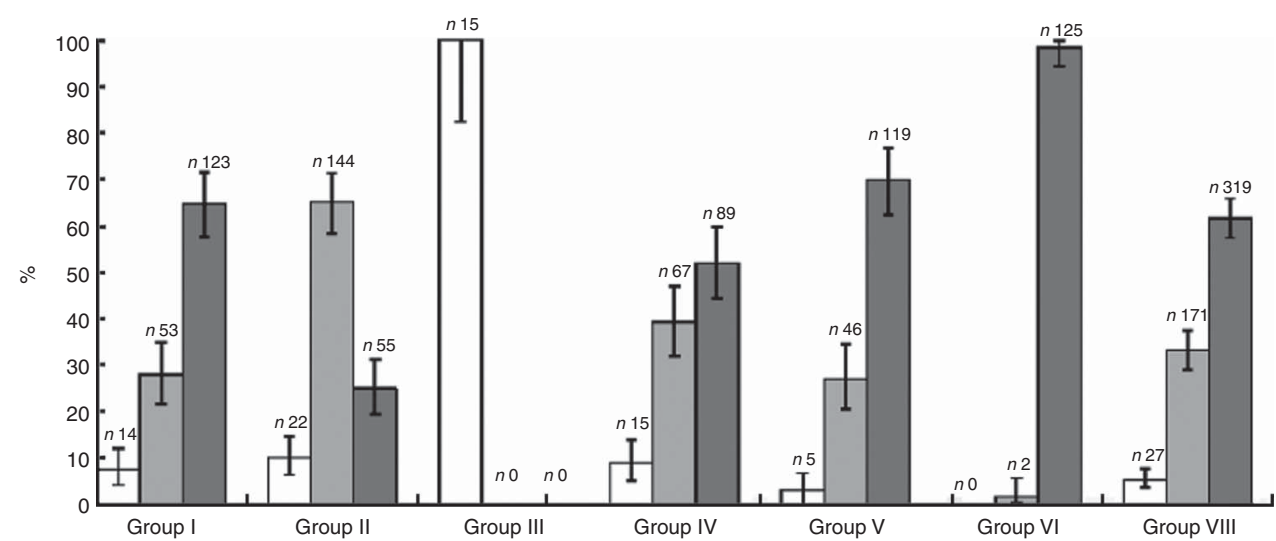

Fig. 1 Classification of groups of processed and ultra-processed pre-prepared meals and prepared ingredients marketed in Brazil, used in lunch or dinner, by sodium content $(\square$, low ( $\leq 120 \mathrm{mg} / 100 \mathrm{~g}$ or $100 \mathrm{ml}) ; \square$, medium (>120 and $\leq 600 \mathrm{mg} / 100 \mathrm{~g} \mathrm{or} 100 \mathrm{ml})$; $\square$, high (>600 mg/100 g or $100 \mathrm{ml})$ ) according to the Traffic Light Labels of the Food Standards Agency, UK ${ }^{(39)}(n$ 1411). Values are percentages with their $95 \%$ confidence intervals represented by vertical bars. Group I=Bread products, cereals, legumes, roots, tubers and their derivatives; Group II=Fresh and canned vegetables; Group III = Fruits, juices, nectars and fruit drinks; Group IV = Milk and derivatives; Group V = Meat and eggs; Group VI = Oils, fats and seeds; Group VIII = Sauces, ready-made seasonings, broths, soups and prepared dishes. No product analysed in the study was part of Group VII of the Brazilian nutrition labelling legislation to describe serving sizes for packaged foods ${ }^{(22)}$, so this group is not reported in the analyses

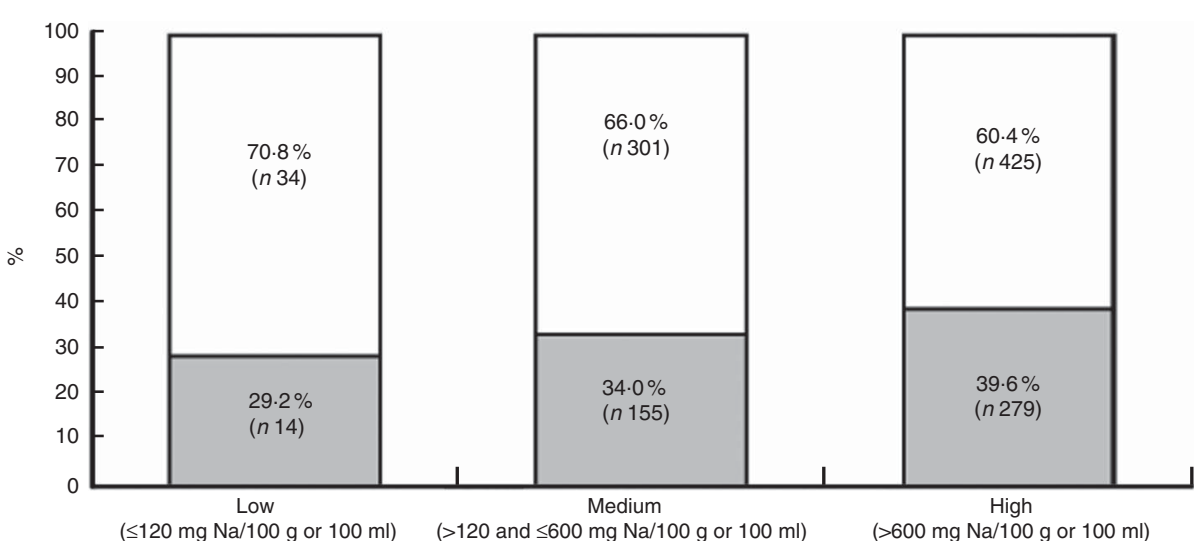

Fig. 2 Association between the first appearance of salt on the ingredients list ${ }^{\star} \square$, first to third position; $\square$, fourth position or more) and the sodium content of processed and ultra-processed pre-prepared meals and prepared ingredients marketed in Brazil, used in lunch or dinner, according to the Traffic Light Labels of the Food Standards Agency, UK ${ }^{(39)}$ ( $n$ 1208). *Excluded products included complete seasonings and those prepared for broth, products belonging to the broth concentrate and soup powder subgroup

Of all products analysed, $14.7 \%(95 \% \mathrm{CI} 10 \cdot 4,20 \cdot 5 \%)$ had at least one compound ingredient recognized for containing salt in its composition (cheeses, condiments/ prepared broths, seasonings in flavoured powders, sauces and others) without describing the composition of these ingredients separately. The presence of compound ingredients with this characteristic was also observed in $81.2 \%$ (95\% CI $71 \cdot 5,90 \cdot 7 \%$ ) of the sixty-nine studied products ( $4.9 \%$ ) for which no citation of salt or $\mathrm{Na}$-containing food additive was found on the ingredients list.

\section{Food additives containing $\mathrm{Na}$}

Similarly, we studied Na-containing food additives cited on the ingredients lists (Table 2).

We found thirty-four different types of Na-containing food additives, resulting in 1764 citations on the ingredients lists of the products analysed. Of these, $52.0 \%$ (95\% CI 48.2, 55.6\%) contained at least one type of $\mathrm{Na}$-containing food additive and the maximum number of Na-containing additives per product was eight $(n 2)$. Sodium caseinate and emulsifying salts were considered additives despite their absence from the International Numbering System because they are additive mixtures. Fourteen products (1.0\%) had incomplete food additive descriptions, precluding the inclusion of these data in the total accounting of food additive citations.

\section{Discussion}

The present study analysed $\mathrm{Na}$ labelling on processed and ultra-processed pre-prepared meals and prepared 
Table 1 Sodium content $(\mathrm{mg} / 100 \mathrm{~g}$ or $100 \mathrm{ml}$ ) and sodium content classification by group and subgroup of processed and ultra-processed pre-prepared meals and prepared ingredients food products marketed in Brazil, used in lunch or dinner $(n$ 1411)

\begin{tabular}{|c|c|c|c|c|c|}
\hline Food product groups and subgroups* & $n$ & Median† & $\begin{array}{l}\text { Na content } \\
\text { classification }\end{array}$ & $\begin{array}{l}\text { Percentiles } \\
\text { (P2-P98)† }\end{array}$ & $\begin{array}{l}\mathrm{P} 98 / \mathrm{P} 2 \\
\text { ratio† }\end{array}$ \\
\hline I - Bread products, cereals, legumes, roots, tubers and their derivatives & 190 & 860 & High & & \\
\hline Instant pasta with or without seasoning & 78 & 1632 & High & 288-2566 & 8.9 \\
\hline Dehydrated pasta with filling & 3 & 590 & Medium & $530-780$ & 1.5 \\
\hline Fresh pasta with and without filling & 50 & 581 & Medium & $43-1099$ & $25 \cdot 6$ \\
\hline Ready-made mixtures for rice/risotto preparation & 12 & 44 & Low & $0-2170 \S$ & 434.0 \\
\hline Ready-made mixtures for flavoured polenta preparation & 5 & 1544 & High & $1530-1704$ & $1 \cdot 1$ \\
\hline Soya-based breaded steak, meatball and hamburger preparations & 10 & 587 & Medium & $506-1000$ & $2 \cdot 0$ \\
\hline Ready-to-consume manioc flour & 13 & 591 & Medium & $337-923$ & $2 \cdot 7$ \\
\hline Frozen filled cheese bread & 1 & 665 & High & & \\
\hline Frozen cheese bread without filling & 6 & 527 & Medium & $302-774$ & $2 \cdot 6$ \\
\hline Tofu & 3 & 320 & Medium & $150-323$ & $2 \cdot 2$ \\
\hline Frozen pre-fried potatoes and cassava & 9 & 335 & Medium & $24-451$ & $18 \cdot 8$ \\
\hline II - Fresh and canned vegetables & 221 & 425 & Medium & & \\
\hline Triple vegetable concentrate (extract) & 27 & 403 & Medium & $302-733$ & 2.4 \\
\hline Vegetable purée or pulp, including tomato & 6 & 68 & Low & $0-260$ & $52 \cdot 0$ \\
\hline Tomato sauce or sauces with bases of tomatoes and other vegetables & 77 & 472 & Medium & $0-1530 \S$ & $306 \cdot 0$ \\
\hline Pickles and capers & 8 & 2167 & High & $713-3110$ & 4.4 \\
\hline Dehydrated vegetable preserves (dried tomatoes) & 3 & 1615 & High & $355-2223$ & $6 \cdot 3$ \\
\hline $\begin{array}{l}\text { Pickled vegetables (artichokes, asparagus, mushrooms, peppers, cucumber } \\
\text { and palm hearts), in brine, vinegar and oil }\end{array}$ & 56 & 424 & Medium & $140-1476$ & $10 \cdot 5$ \\
\hline $\begin{array}{l}\text { Garnishes and other canned vegetables and fruits (carrots, peas, corn, } \\
\text { peeled tomatoes and others) }\end{array}$ & 62 & 371 & Medium & 0-3170 & $634 \cdot 0$ \\
\hline III - Fruits, juices, nectars and fruit drinks & 15 & 0 & Low & & \\
\hline Fruit preserves, including fruit salad & 15 & 0 & Low & $0-30 \S$ & $6 \cdot 0$ \\
\hline IV - Milk and derivatives & 171 & 633 & High & & \\
\hline Grated cheese & 26 & 707 & High & $50-1660$ & 33.2 \\
\hline Minas cheese & 18 & 319 & Medium & $133-1833$ & 13.8 \\
\hline $\begin{array}{l}\text { Other cheeses (ricotta, semi-hard, white, cream cheese, melted and } \\
\text { paste) }\end{array}$ & 127 & 637 & High & $50-1800$ & $36 \cdot 0$ \\
\hline$V$ - Meats and eggs & 170 & 877 & High & & \\
\hline Meat preparations with flour or breading & 32 & 650 & High & 149-932 & $6 \cdot 3$ \\
\hline Meat preparations - seasoned, smoked and cooked or pre-cooked & 18 & 767 & High & $100-1483$ & 14.8 \\
\hline Sausages, ham and cold ham & 35 & 1700 & High & $885-3638$ & $4 \cdot 1$ \\
\hline Sausages, all kinds & 50 & 1067 & High & $370-1575$ & $4 \cdot 3$ \\
\hline Kani-kama & 3 & 718 & High & $615-885$ & 1.4 \\
\hline Tuna, sardines, fish, shellfish, other fish pickled with or without sauces & 28 & 317 & Medium & $152-1020$ & 6.7 \\
\hline Pickled eggs & 4 & 56 & Low & $56-56$ & 1.0 \\
\hline VI - Oils, fats and seeds & 127 & 1550 & High & & \\
\hline Olives & 62 & 1650 & High & $820-2400$ & 2.9 \\
\hline Mayonnaise and mayonnaise-based sauces & 35 & 1050 & High & $708-1233$ & 1.7 \\
\hline Oil-based salad dressings (all kinds) & 30 & 1119 & High & $383-6000$ & $15 \cdot 7$ \\
\hline $\begin{array}{l}\text { VIII - Sauces, ready-to-consume seasonings, broths, soups and prepared } \\
\text { dishes }\end{array}$ & 522 & 873 & High & & \\
\hline $\begin{array}{l}\text { Concentrated broths (meat, chicken, vegetable, and others) and soup } \\
\text { powders }\end{array}$ & 95 & 4500 & High & 2384-23726 & $10 \cdot 0$ \\
\hline Ketchup and mustard & 41 & 717 & High & $0-2975 \S$ & 595.0 \\
\hline Soya- or vinegar-based sauces & 67 & 2836 & High & $100-5490$ & $54 \cdot 9$ \\
\hline Sauces based on dairy or broth products & 30 & 544 & Medium & $50-3556$ & $71 \cdot 1$ \\
\hline Powders to prepare sauces & 8 & 4442 & High & $3903-4978$ & 1.3 \\
\hline Miso soup & 2 & 4585 & High & $4530-4640$ & 1.0 \\
\hline Missoshiru & 2 & 6980 & High & $6910-7050$ & 1.0 \\
\hline Prepared and semi-prepared dishes not included in other table items & 208 & 475 & Medium & $54-1170$ & $21 \cdot 7$ \\
\hline Complete seasonings & 69 & 18700 & High & $2620-40300$ & $15 \cdot 4$ \\
\hline
\end{tabular}

${ }^{*}$ Food product groups and subgroups according to RDC no. 359/2003 ${ }^{(22)}$.

$\dagger \mathrm{Na}$ in $\mathrm{mg} / 100 \mathrm{~g}$ or $\mathrm{mg} / 100 \mathrm{ml}$.

$\ddagger$ Median Na content classified according to the Traffic Light Labels of the Food Standards Agency, UK ${ }^{(39)}$

$\S$ To facilitate calculation, in the cases in which the minimum value is zero, the minimum value was considered $=5 \mathrm{mg} \mathrm{Na} / 100 \mathrm{~g}$, according to RDC no. 360 / $2003^{(23)}$.

ingredients marketed in Brazil, used in lunch or dinner. Approximately $60 \%$ of the products analysed had high Na content $(>600 \mathrm{mg} / 100 \mathrm{~g}$ ) and this high content occurred in practically all food product groups, especially those in group VIII: complete seasonings (18 700 mg Na/100 g), broths and soup powders ( $4500 \mathrm{mg} \mathrm{Na} / 100 \mathrm{~g}$ ) and powders for sauce preparation ( $4442 \mathrm{mg} \mathrm{Na} / 100 \mathrm{~g}$ ).
Studies conducted in other countries have also found high $\mathrm{Na}$ content in processed food products. In Canada, $17 \%$ of the 364 products with $\mathrm{Na}$ information analysed had high $\mathrm{Na}$ content ${ }^{(40)}$. In the UK, the highest mean $\mathrm{Na}$ content was found in broths and sauces $(1090 \mathrm{mg} /$ $100 \mathrm{~g})^{(30)}$. In Australia the mean Na content of broths was $6108 \mathrm{mg} / 100 \mathrm{~g}^{(29)}$. Another Australian study ${ }^{(41)}$ observed 
Table 2 Food additives containing sodium cited on the ingredients lists of processed and ultra-processed pre-prepared meals and prepared ingredients marketed in Brazil, used in lunch or dinner meals, along with their citation frequency and respective International Numbering System (INS) ${ }^{(34,35)}$ (n 1416)

\begin{tabular}{|c|c|c|c|}
\hline Food additives containing $\mathrm{Na}$ & INS & $n$ & $\%$ \\
\hline Monosodium glutamate & 621 & 505 & $35 \cdot 7$ \\
\hline Disodium 5 '-inosinate & 631 & 208 & $14 \cdot 7$ \\
\hline Pentasodium triphosphate & $451 \mathrm{i}$ & 144 & $10 \cdot 7$ \\
\hline Sodium erythorbate (sodium isoascorbate) & 316 & 103 & $7 \cdot 3$ \\
\hline Sodium benzoate & 211 & 83 & 5.9 \\
\hline Sodium nitrite & 250 & 81 & $5 \cdot 7$ \\
\hline Sodium polyphosphate & $452 i$ & 58 & $4 \cdot 1$ \\
\hline Sodium nitrate & 251 & 55 & 3.9 \\
\hline Tetrasodium diphosphate & $450 \mathrm{iii}$ & 55 & 3.9 \\
\hline Disodium $5^{\prime}$-guanylate & 627 & 53 & 3.7 \\
\hline Sodium carbonate & 500 & 52 & 3.7 \\
\hline Calcium disodium ethylene diamine tetraacetate & 385 & 48 & 3.4 \\
\hline Carrageenan & 407 & 45 & 3.2 \\
\hline Sodium dihydrogen phosphate & $339 \mathrm{i}$ & 41 & $2 \cdot 8$ \\
\hline Trisodium citrate & 331iii & 36 & 2.5 \\
\hline Disodium diphosphate & $450 \mathrm{i}$ & 35 & 2.5 \\
\hline Trisodium phosphate & 339iii & 21 & 1.5 \\
\hline Sodium lactate & 325 & 20 & 1.4 \\
\hline Sodium saccharin & 954 & 19 & 1.3 \\
\hline Disodium hydrogen phosphate & $339 \mathrm{ii}$ & 18 & 1.3 \\
\hline Sodium stearoyl lactylate & $481 \mathrm{i}$ & 17 & 1.2 \\
\hline Sodium metabisulfite & 223 & 15 & $1 \cdot 1$ \\
\hline Sodium aluminosilicate & 554 & 10 & 0.7 \\
\hline Sodium carboxymethyl cellulose (cellulose gum) & 466 & 8 & 0.6 \\
\hline Sodium alginate & 401 & 6 & 0.4 \\
\hline Sodium hydrogen carbonate & $500 \mathrm{ii}$ & 5 & 0.4 \\
\hline Sodium caseinate & & 5 & 0.4 \\
\hline Sodium cyclamate & 952 & 4 & 0.3 \\
\hline Sodium diphosphate ${ }^{*}$ & $540 \mathrm{i}$ & 3 & 0.2 \\
\hline Emulsifying salts & & 3 & 0.2 \\
\hline Sodium ascorbate & 301 & 3 & 0.2 \\
\hline Sodium acetate & $262 \mathrm{i}$ & 2 & 0.1 \\
\hline Sodium hydrogen sulfite & 222 & 2 & 0.1 \\
\hline Sodium sulfite & 221 & 1 & 0.07 \\
\hline
\end{tabular}

${ }^{*}$ Does not appear on Mercosul's list of food additives ${ }^{(35)}$.

high mean $\mathrm{Na}$ content in broths $(16920 \mathrm{mg} / 100 \mathrm{~g})$ and soup powders (1882 mg/100 g). In a New Zealand study, the highest mean $\mathrm{Na}$ content was found in Asian sauces (5141 mg/100 g), mustard (1779 mg/100 g) and hot sauces $(1549 \mathrm{mg} / 100 \mathrm{~g})^{(42)}$.

Despite having some of the highest mean Na levels in the present study and being constituted basically of salt, complete seasonings and broths are not consumed in large amounts within a single meal. Nevertheless, these products are among the main $\mathrm{Na}$ sources in the Brazilian diet $^{(2)}$. Furthermore, a meal can be comprised of several types of food products ${ }^{(15)}$, containing a combination of high-Na processed foods. One example of this is pasta with tomato sauce, which can be composed of instant noodles, ready-made tomato sauce, pickled olives, readymade seasoning and grated cheese, and served with a side salad with ready-made dressing and cooked meat ready to be heated - all products with a potentially high $\mathrm{Na}$ content. In a meal with this combination, for example, the Na content could exceed the recommended levels, compromising nutritional quality ${ }^{(5)}$.

A large variation was also found in $\mathrm{Na}$ content between similar products. In $78.0 \%$ of the subgroups analysed, the variation between the highest and lowest $\mathrm{Na}$ content was at least twofold and could reach extreme differences, such as 634 times greater in the case of the garnishes and other canned vegetables and fruits subgroup. In some subgroups (such as oil-based salad dressings), these large differences concurred with high $\mathrm{Na}$ content.

An Australian study ${ }^{(29)}$ that analysed 7221 processed foods also found high $\mathrm{Na}$ content and large variations in $\mathrm{Na}$ concentration in most product categories analysed, including salad dressings (181 times). A Brazilian study of the nutritional profiles of some processed foods ${ }^{(43)}$ found similar results, but with shoestring potatoes presenting the greatest variation ( 14.3 times). The present study found even greater variation between the Na levels of similar products, which may have occurred in some subgroups due to the inclusion of distinct products in the same subgroup. The resulting data asymmetry caused by this categorization can be observed in the 'other cheeses' subgroup, which includes both an example of ricotta cheese with $\mathrm{Na}$ content $<100 \mathrm{mg} / 100 \mathrm{~g}$ and an example of parmesan cheese with $\mathrm{Na}$ content $>2000 \mathrm{mg} / 100 \mathrm{~g}$. However, in most of the subgroups the difference is attributable to the presence of products with insignificant 
amounts of $\mathrm{Na}$ according to Brazilian legislation in contrast with similar products with extreme $\mathrm{Na}$ levels in the same subgroup, as is the case for tomato sauces, for example.

The large variation found shows that there are real opportunities to reformulate products available for sale in Brazil. This situation demands a strong government policy to reduce $\mathrm{Na}$ content ${ }^{(44)}$, as has occurred in the UK and Finland ${ }^{(18)}$, and has been occurring in Brazil since $2010^{(45)}$. Such policies involve the reformulation of food products in order to reduce the supply - and thus the intake - of $\mathrm{Na}$ coming from these products. These policies, combined with new proposals to require nutritional labelling on the front of packages, can influence the industry to reduce the $\mathrm{Na}$ levels of the foods they offer ${ }^{(31,32)}$.

Equally noteworthy is the high number of citations of Na-containing food additives in the products studied, especially monosodium glutamate. According to a study developed in China, monosodium glutamate intake was positively and longitudinally associated with BMI and overweight among apparently healthy Chinese adults ${ }^{(46)}$. In addition, up to eight $\mathrm{Na}$-containing food additives were found in the same product - as in the case of cooked meat with barbeque sauce (group V) - as well as sodium diphosphate, which is not included on Mercosul's harmonized list of additives and was found in $0.3 \%$ of the food analysed. A review of food additives ${ }^{(47)}$ raises the issue of adverse health effects caused by the use of food additives in large amounts.

The reduction of all dietary $\mathrm{Na}$ sources (including food additives) is recommended by the $\mathrm{WHO}^{(6)}$. In order to reduce $\mathrm{Na}$ intake, it is recommended to inform the public of high $\mathrm{Na}$ levels in foods ${ }^{(25)}$, facilitating identification of high-Na foods at the time of purchase. However, the feasibility of this is questionable considering the way $\mathrm{Na}$ is currently labelled in Brazil.

The Brazilian consumer currently has two ways to check for excessive $\mathrm{Na}$ content in processed foods: (i) by reading $\mathrm{Na}$ information in milligrams per serving along with analysing the \%DV corresponding to the food's serving size; or (ii) by noting the appearance of Na-containing foods (especially salt) on the ingredients list. The present study identified some points that could hinder this examination.

The first point was the presentation of $\mathrm{Na}$ content in milligrams per serving. The present study's analyses were only made possible after converting the Na value in milligrams per serving to milligrams per $100 \mathrm{~g}$ or $100 \mathrm{ml}$ of food. Interpretation was made difficult by the manner in which nutrition label information is presented (with varying serving sizes) and the fact that Brazilian nutrition labelling legislation ${ }^{(22)}$ permits serving size variability. It should be noted that the public generally does not understand information in milligrams or the conversion of $\mathrm{Na}$ to salt. Furthermore, the terms 'sodium' and 'salt' are still erroneously used as synonyms ${ }^{(48,49)}$. One suggested alternative is to present $\mathrm{Na}$ content per $100 \mathrm{~g}$ instead of by serving size precisely because of the variability allowed in serving sizes, which in many cases prevents easy comparison between foods ${ }^{(50)}$.

Another difficulty concerns the \%DV calculation based on $2400 \mathrm{mg} \mathrm{Na} / \mathrm{d}^{(23)}$. The use of this value extrapolates the WHO and $\mathrm{FAO}^{(17)}$ recommended daily intake by $400 \mathrm{mg}$. The presentation of a value above the recommended value can confuse consumers, as discussed in a review of $\mathrm{Na}$ intake in Canada ${ }^{(49)}$.

Finally, it was expected that higher $\mathrm{Na}$ content could correspond to a higher number of salt citations in the initial position of the ingredients list. However, the present study did not find this rule to be a good indicator to check for high $\mathrm{Na}$ levels in food products because, among other reasons, the proportion of added salt is still small compared with the proportion of other ingredients added to the product, such as processed food with few ingredients like tomato purée (made with tomatoes and salt) or food products with an elevated proportion of a main ingredient, such as flour or meat. A Chinese study ${ }^{(51)}$ that analysed the ingredients lists of 5877 food products found salt listed as one of the first three ingredients on $22.9 \%$ of them, yet highlighted the difficulty in judging product quality simply by reading the ingredients list and consequently consumers' difficulty in identifying processed food ingredients related to the development of chronic non-communicable diseases.

Our study also incorporates some possible limitations that should be taken into consideration. One possible limitation of the present study is the use of nutrition labelling to determine a product's $\mathrm{Na}$ content without running chemical analyses. However, the study considered that consumers only have access to what is reported on packaging, so the accuracy of such information should be ensured by the manufacturer and tested for compliance with the legislation ${ }^{(23)}$. Another potential limitation of the study was the inclusion of products sold in just a single store, but since the store is a large supermarket in an urban area that offers a wide variety of food products and belongs to a large chain, most of the products sold there are sold by other chains and stores throughout the country, so this fact is unlikely to affect the study's external validity. Finally, the products' presentation in predefined groups and subgroups by Brazilian labelling legislation can also be considered a limitation. However, despite making it impossible to specifically analyse each type of food product, the study settled on using the predefined groups and subgroups because this is the official categorization under current labelling law in Brazil ${ }^{(22)}$, which regulates the presentation format of nutritional information available at the time of purchase.

\section{Conclusions}

Most of the processed and ultra-processed food products included in the present study had high $\mathrm{Na}$ content and 
high variability among similar products, which presents new evidence for reformulation opportunities in food products sold in Brazil. These products are widely consumed by Brazilians, underscoring the urgency of reducing $\mathrm{Na}$ content in these products as excessive $\mathrm{Na}$ consumption has a negative impact on health outcomes, including an increased risk of developing chronic noncommunicable diseases. It is clear that $\mathrm{Na}$ labelling should be reviewed, since current labelling was found not to facilitate the identification of $\mathrm{Na}$ content or its variation among similar products. Aiming to ensure the usefulness of information provided to consumers and the nutritional quality of products sold, we recommend a reduction of $\mathrm{Na}$ content in food products in Brazil as well as the continued development of studies aiming to improve Brazilian $\mathrm{Na}$ labelling, with a focus on easier identification of high-Na products at the time of purchase.

\section{Acknowledgements}

Financial support: This research was supported by the Council for the Development of Postgraduate Personnel (Coordenação de Aperfeiçoamento de Pessoal de Nível Superior; CAPES) and the Santa Catarina State Research and Technological Innovation Assistance Foundation (Fundação de Amparo à Pesquisa e Inovação Tecnológica do Estado de Santa Catarina; FAPESC). CAPES and FAPESC had no role in the design, analysis or writing of this article. Conflict of interest: None. Authorship: C.A.M. was responsible for the study design, project management, data analysis, interpretation of the results and manuscript writing. D.A.G.-C. was responsible for the data analysis, interpretation of the results and revision of the final manuscript. R.P.d.C.P., A.A.d.S. and M.B.V. were responsible for the design of the original study, research coordination, orientation and revision of the final manuscript. Ethics of buman subject participation: Ethical approval was not required.

\section{References}

1. US Department of Agriculture \& US Department of Health and Human Services (2010) Dietary Guidelines for Americans. http://www.health.gov/dietaryguidelines/dga2010/ DietaryGuidelines2010.pdf (accessed March 2011).

2. Sarno F, Claro RM, Levy-Costa RB et al. (2009) Estimated sodium intake by the Brazilian population, 2002-2003. Rev Saude Publica 43, 219-225.

3. Brown IJ, Tzoulaki I, Candeias V et al. (2009) Salt intakes around the world: implications for public health. Int $J$ Epidemiol 38, 791-813.

4. Tanase CM, Griffin P, Koski KG et al. (2011) Sodium and potassium in composite food samples from the Canadian Total Diet Study. J Food Compost Anal 24, 237-243.

5. Instituto Brasileiro de Geografia e Estatística (2011) Pesquisa de Orçamentos Familiares 2008-2009: Analise do consumo alimentar pessoal no Brasil. Rio de Janeiro: IBGE.
6. World Health Organization (2007) Reducing salt intake in populations. Report of a WHO Forum and Technical Meeting. http://www.who.int/dietphysicalactivity/Salt_Report_ VC_april07.pdf (accessed May 2011).

7. Uzan A \& Delaveau P (2009) The salt content of food: a public health problem. Ann Pharmaceut Franc 67, 291-294.

8. Anderson CAM, Appel LJ, Okuda N et al. (2010) Dietary sources of sodium in China, Japan, the United Kingdom, and the United States, women and men 40 to 59 years: The INTERMAP Study. J Am Diet Assoc 110, 736-745.

9. Monteiro CA, Levy-Costa RB, Claro RM et al. (2010) A new classification of foods based on the extent and purpose of their processing. Cad Saude Publica 26, 2039-2049.

10. Monteiro CA, Levy-Costa RB, Claro RM et al. (2011) Increasing consumption of ultra-processed foods and likely impact on human health: evidence from Brazil. Public Health Nutr 14, 5-13.

11. Hoy MK, Goldman JD, Murayi T et al. (2011) Sodium intake of the US population: What We Eat in America, NHANES 2007-2008. http://www.ars.usda.gov/sp2userfiles/place/ 12355000/pdf/dbrief/sodium_intake_0708.pdf （accessed March 2012).

12. Instituto Brasileiro de Geografia e Estatística (2010) Pesquisa de Orçamentos Familiares 2008-2009: Aquisiçao alimentar domiciliar per capita. Rio de Janeiro: IBGE.

13. Levy-Costa RB, Sichieri R, Pontes NS et al. (2005) Household food availability in Brazil: distribution and trends (1974-2003). Rev Saude Publica 39, 530-540.

14. Maciel MA (2004) Uma cozinha a brasileira. Est Hist 33, 25-39.

15. Barbosa L (2007) Feijao com arroz e arroz com feijao: o Brasil no prato dos brasileiros. Horiz Antropol 13, 87-116.

16. Brasil, Ministerio da Saude, Secretaria de Atençao a Mulher, Departamento de Atençao Brasilía (2012) National Policy for Food and Nutrition. Brasília, DF: Ministerio da Saude.

17. World Health Organization (2003) Diet, Nutrition and the Prevention of Chronic Diseases. Joint WHO/FAO Expert Consultation. WHO Technical Report Series no. 916. Geneva: WHO.

18. Webster JL, Dunford EK, Hawkes C et al. (2011) Salt reduction initiatives around the world. J Hypertens 29, 1043-1050.

19. World Health Organization (2004) Global Strategy on Diet, Physical Activity and Health. Fifty-seventh World Health Assembly. List of All Documents and Publications. http:// www.who.int/hpr/gs.all.docs.shtml (accessed June 2009).

20. World Health Organization \& Food and Agriculture Organization of the United Nations (2007) Food Labelling, 5th ed. Rome: FAO; available at ftp://ftp.fao.org/docrep/ fao/010/a1390e/a1390e00.pdf

21. Brasil, Ministerio da Saude, Agencia Nacional de Vigilancia Sanitária (2000) Resoluçao da Diretoria Colegiada - RDC no. 94 de 23 de dezembro de 2000: aprova regulamento tecnico para rotulagem nutricional obrigatoria de alimentos e bebidas embalados. Brasília, DF: Diario Oficial [da] Republica Federativa do Brasil, Poder Executivo.

22. Brasil, Ministerio da Saude, Agencia Nacional de Vigilancia Sanitaria (2003) Resoluçao da Diretoria Colegiada - RDC no. 359 de 23 de dezembro de 2003: aprova regulamento tecnico de porções de alimentos embalados para fins de rotulagem nutricional. Brasília, DF: Diario Oficial [da] Republica Federativa do Brasil, Poder Executivo.

23. Brasil, Ministerio da Saude, Agencia Nacional de Vigilancia Sanitaria (2003) Resoluçao da Diretoria Colegiada - RDC no. 360 de 23 de dezembro de 2003: aprova regulamento tecnico sobre rotulagem nutricional de alimentos embalados, tornando obrigatoria a rotulagem nutricional. Brasília, DF: Diario Oficial [da] Republica Federativa do Brasil, Poder Executivo. 
24. Brasil, Ministerio da Saude, Agencia Nacional de Vigilancia Sanitaria (2002) Resoluçao da Diretoria Colegiada - RDC no. 259 de 20 de dezembro de 2002: aprova regulamento tecnico para rotulagem de alimentos embalados. Brasília, DF: Diario Oficial [da] Republica Federativa do Brasil, Poder Executivo.

25. Brasil Ministerio da Saude (2008) Feeding Guide for the Brazilian Population: Promoting the Health Food. Brasília, DF: Ministerio da Saude.

26. National Health Service, NHS Choices (2013) Food labels. http://www.nhs.uk/Livewell/Goodfood/Pages/food-labelling. aspx\#In (accessed April 2012).

27. Han H (2012) Low sodium diet. J Renal Nutr 22, e11-e13.

28 Pietinen P, Valsta LM, Hirvonen T et al. (2008) Labelling the salt content in foods: a useful tool in reducing sodium intake in Finland. Public Health Nutr 11, 335-340.

29. Webster JL, Dunford JK \& Neal BC (2010) A systematic survey of the sodium contents of processed foods. Am J Clin Nutr 91, 413-420

30. Ni Murchu C, Capelin C, Dunford EK et al. (2011) Sodium content of processed foods in the United Kingdom: analysis of 44,000 foods purchased by 21,000 households. Am J Clin Nutr 93, 594-600.

31. van Raaij J, Hendriksen M \& Verhagen H (2009) Potential for improvement of population diet through reformulation of commonly eaten foods. Public Health Nutr 12, 325-330.

32. Vyth EL, Steenhuis IHM, Roodenburg AJC et al. (2010) Frontof-pack nutrition label stimulates healthier product development: a quantitative analysis. Int J Behav Nutr Phys Act 7, 65.

33. Associaçao Brasileira de Supermercados (2013) Ranking Abras: as 500 maiores. http://www.alasnet.org/alas/images/ asociados/abras/ranking\%20abras\%202013esp.pdf (accessed July 2013).

34. Brasil, Ministerio da Saude, Agencia Nacional de Vigilancia Sanitaria (2010) Resoluçao da Diretoria Colegiada RDC no. 45 de 03 de novembro de 2010: aprova regulamento tecnico sobre aditivos alimentares autorizados segundo as Boas Praticas de Fabricaçao (BPF). Brasília, DF: Diario Oficial [da] Republica Federativa do Brasil, Poder Executivo.

35. Brasil, Agencia Nacional de Vigilancia Sanitaria (2011) Lista Geral Harmonizada no Mercosul de Aditivos Alimentares e suas Classes Funcionais. http://portal.anvisa.gov.br/wps/ wcm/connect/eacf2e004745977ea06cf43fbc4c6735/Tabela_ Aditivo_GMC11-2006_LGH.pdf?MOD=AJPERES (accessed October 2011)

36. Galeazzi MAM, Domene SMA \& Sichieri R (organizers) (1997) Estudo Multicentrico sobre Consumo Alimentar. http://www.unicamp.br/nepa/arquivo_san/cadernosespecial. pdf (accessed August 2011).

37. Federaçao das Industrias do Estado de Sao Paulo \& Instituto Brasileiro de Opiniao Publica (2010) Brazil Food
Trends 2020. http://www.brasilfoodtrends.com.br/ (accessed September 2011).

38. Souza AM, Pereira RA, Yokoo EM et al. (2013) Most consumed foods in Brazil: National Dietary Survey 2008-2009. Rev Saude Publica 47, 1 Suppl., 190S-199S.

39. Food Standards Agency, UK (2007) Front of pack traffic light signpost labelling technical guidance. http://www.food.gov. uk/multimedia/pdfs/frontofpackguidance2.pdf (accessed May 2011)

40. Elliott C (2008) Assessing 'fun foods': nutritional content and analysis of supermarket foods targeted at children. Obes Rev 9, 368-377.

41. Grimes CA, Campbell KJ, Riddell LJ et al. (2011) Sources of sodium in Australian children's diets and the effect of the application of sodium targets to food products to reduce sodium intake. Br J Nutr 105, 468-477.

42. Woodward E, Eyles H \& Ni Murchu C (2012) Key opportunities for sodium reduction in New Zealand processed foods. Aust N Z J Public Health 36, 84-89.

43. Brasil, Agencia Nacional de Vigilancia Sanitaria (2013) Informe Tecnico no. 54 de julho de 2013: teor de sodio nos alimentos processados. http://portal.anvisa.gov.br/wps/wcm/ connect/8ab9538040695edd83fed3dc5a12ff52/INFORME+T $\%$ C3\%89CNICO+JULHO+2013.pdf?MOD=AJPERES (accessed July 2013).

44. Webster J, Dunford E, Kennington S et al. (2014) Drop the Salt! Assessing the impact of a public health advocacy strategy on Australian government policy on salt. Public Health Nutr 17, 212-218.

45. Brasil Ministerio da Saude (2011) Construção da agenda de reformulaçao de alimentos processados com as industrias de alimentaçao. http://www.nutrição.saude.gov.br/sódio_ reformulacao.php (accessed October 2011).

46. He K, Du S, Xun P et al. (2011) Consumption of monosodium glutamate in relation to incidence of overweight in Chinese adults: China Health and Nutrition Survey (CHNS). Am J Clin Nutr 93, 1328-1336.

47. Polônio MLT \& Peres F (2009) Food additive intake and health effects: public health challenges in Brazil. Cad Saude Publica 25, 1653-1666.

48. McLean R \& Hoek J (2014) Sodium and nutrition labelling: a qualitative study exploring New Zealand consumers' food purchasing behaviours. Public Health Nutr 17, 1138-1146.

49. Van Vliet BN \& Campbell NRC (2011) Efforts to reduce sodium intake in Canada: why, what, and when? Can J Cardiol 27, 437-445.

50. Sharp D (2004) Labelling salt in food: if yes, how? Lancet 364, 2079-2080.

51. Ly J, Chen Y, Wang S et al. (2011) A survey of nutrition labels and fats, sugars, and sodium ingredients in commercial packaged foods in Hangzhou, China. Public Health Reports 126, 116-122. 